\title{
Synthesis of Decaline-Type Thermal-Stable Jet Fuel Additives with Cycloketones
}

Ran Wang,,$^{\dagger} \S$ Guangyi Li, ${ }^{\dagger}$ Hao Tang, ${ }^{\dagger}$ Aiqin Wang, ${ }^{\dagger} \|$ Guoliang Xu, ${ }^{\dagger}$ Yu Cong, ${ }^{\dagger}$ Xiaodong Wang, ${ }^{\dagger}$ Tao Zhang, ${ }^{\dagger,}$ and Ning $\mathrm{Li}^{*}{ }^{\dagger}, \|$

${ }^{\dagger}$ CAS Key Laboratory of Science and Technology on Applied Catalysis and ${ }^{\ddagger}$ State Key Laboratory of Catalysis, Dalian Institute of Chemical Physics, Chinese Academy of Sciences, No. 457 Zhongshan Road, Dalian 116023, China.

$\S$ University of Chinese Academy of Sciences, 19 A Yuquan Road, Shijingshan District, Beijing 100049, China.

॥ Dalian National Laboratory for Clean Energy, No. 457 Zhongshan Road, Dalian 116023, China.

E-mail address of the corresponding author: lining@ dicp.ac.cn (N. Li)

KEYWORDS: lignocellulose, thermal stable, jet fuel additive, decalin, cycloketone

The number of pages: 30 ;

The number of figures: 24 ;

The number of schemes: 1 ;

The number of tables: 3 . 


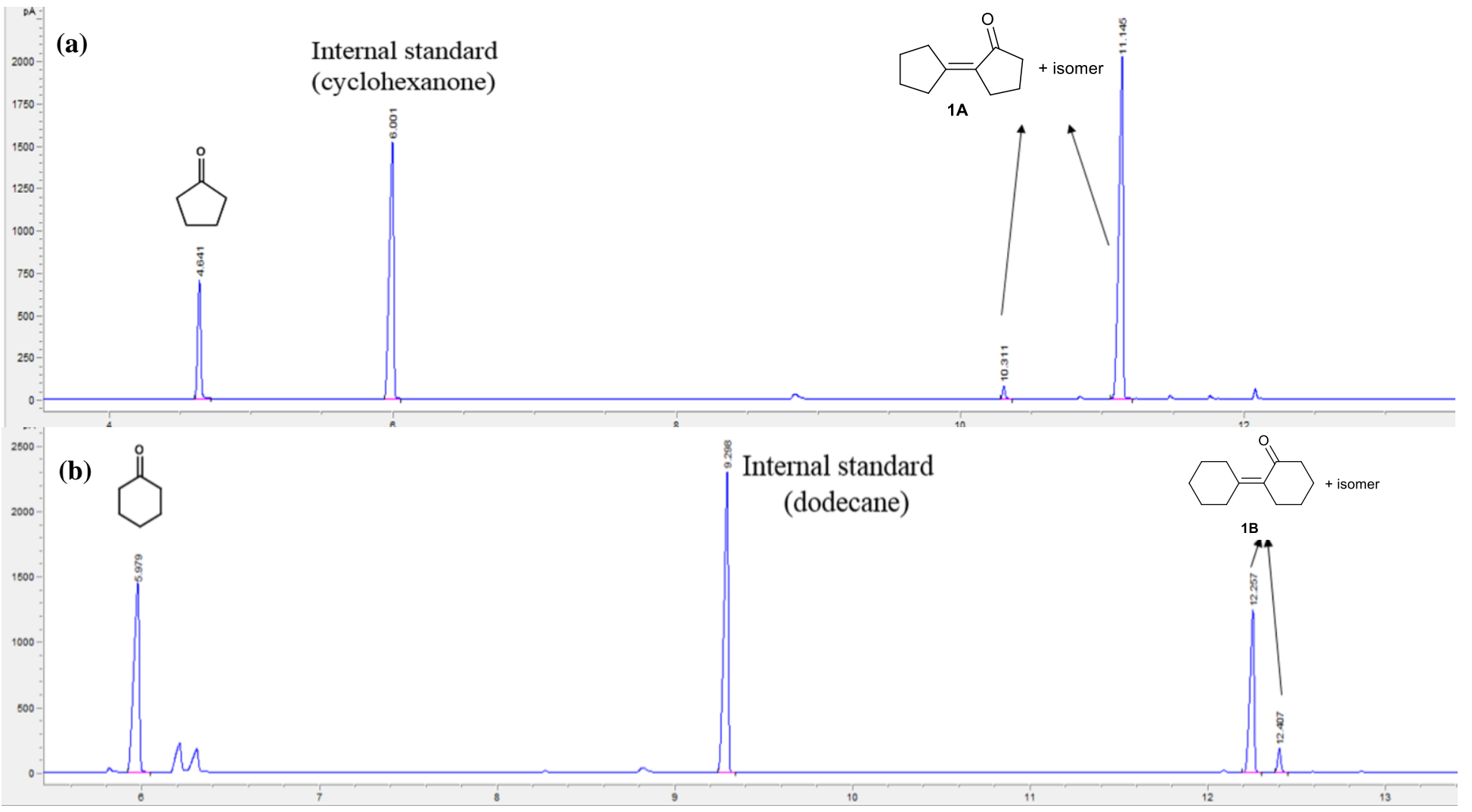

Figure S1. GC chromatograms of the solvent-free self-aldol condensation products of (a) cyclopentanone and (b) cyclohexanone over EAOAc ionic liquid catalyst. Reaction conditions: $373 \mathrm{~K}, 6 \mathrm{~h} ; 10 \mathrm{mmol}$ cyclopentanone (or cyclohexanone) and 1 mmol EAOAc ionic liquid catalyst were used in the tests. 


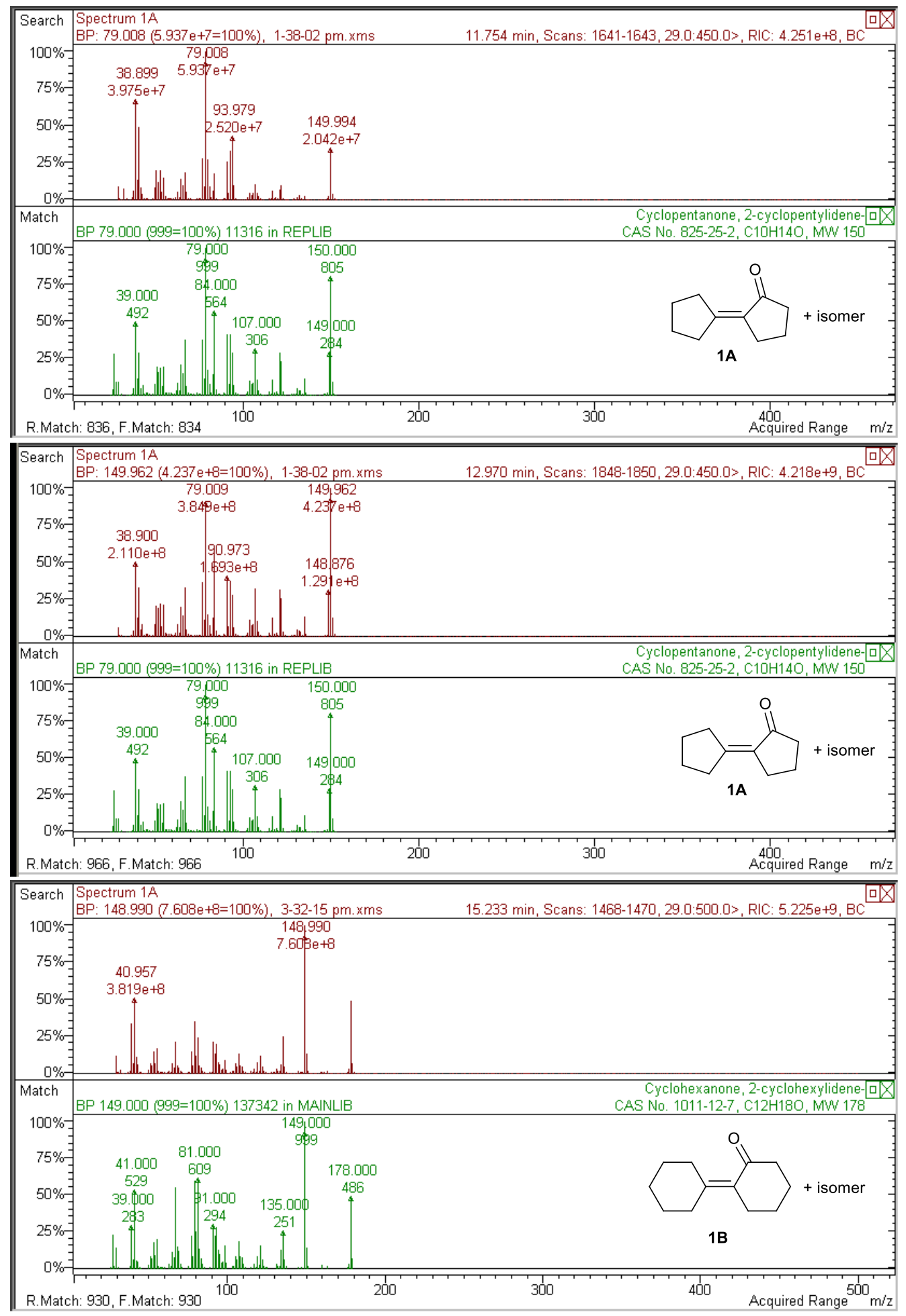

Figure S2. Mass spectrograms of $\mathbf{1 A}$ and 1B from the solvent-free self-aldol condensation of cyclopentanone (or cyclohexanone) over EAOAc ionic liquid catalyst. 

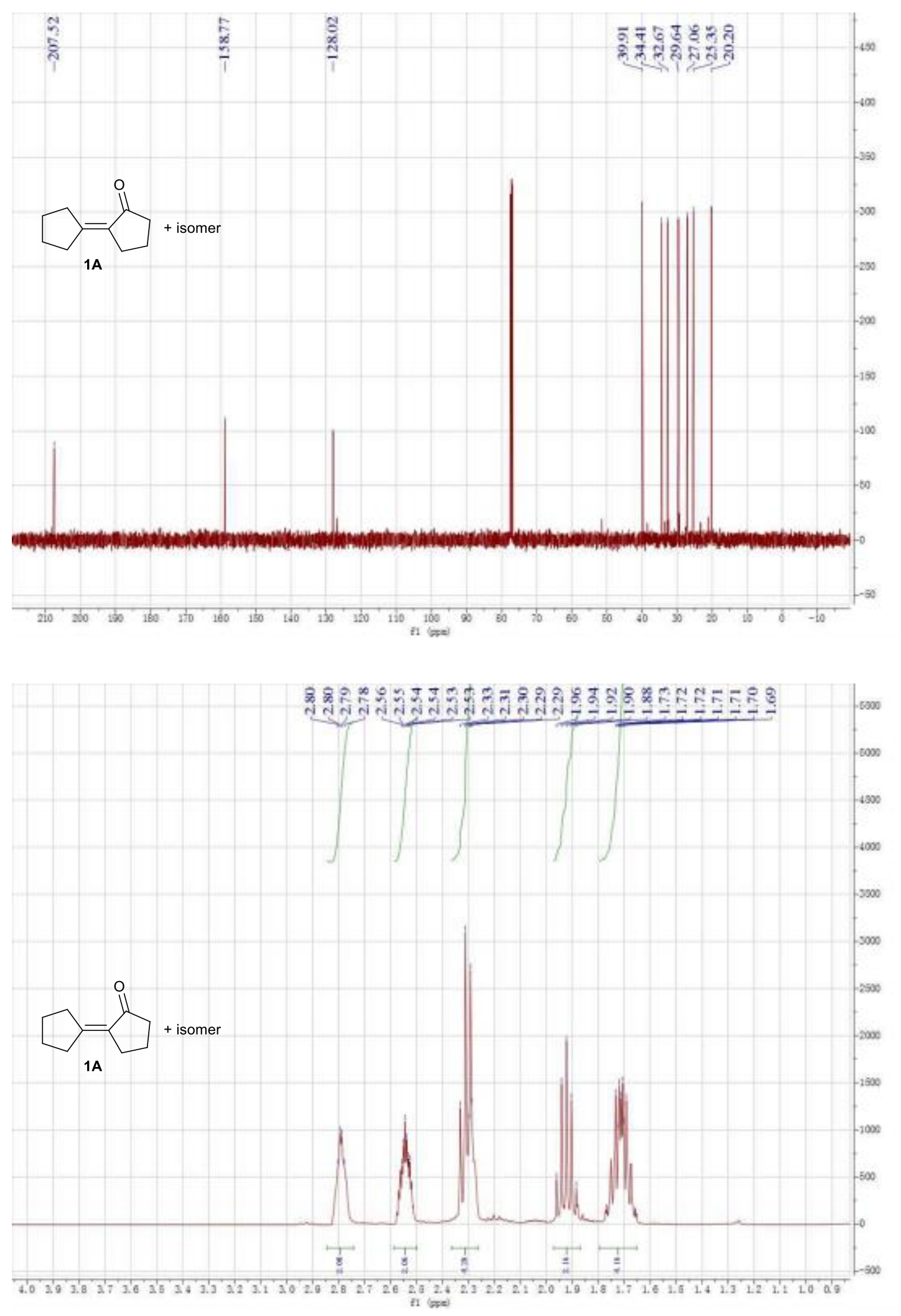

Figure S3. ${ }^{13} \mathrm{C}$ NMR and ${ }^{1} \mathrm{H}$ NMR spectra of $\mathbf{1 A}$ from the solvent-free self-aldol condensation of cyclopentanone over EAOAc ionic liquid catalyst. 

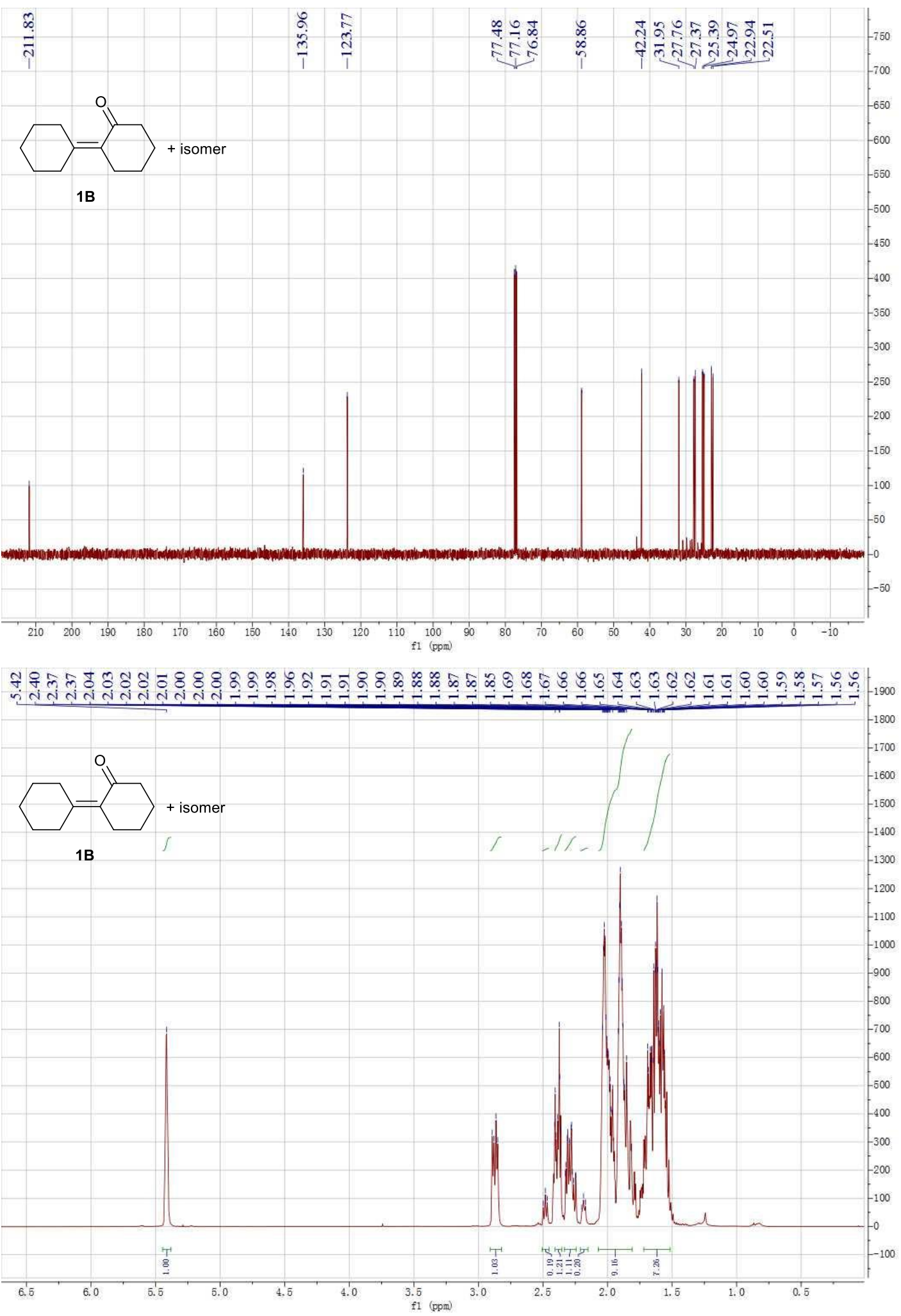

Figure S4. ${ }^{13} \mathrm{C}$ NMR and ${ }^{1} \mathrm{H}$ NMR spectra of $1 B$ from the solvent-free self-aldol condensation of cyclohexanone over EAOAc ionic liquid catalyst. 


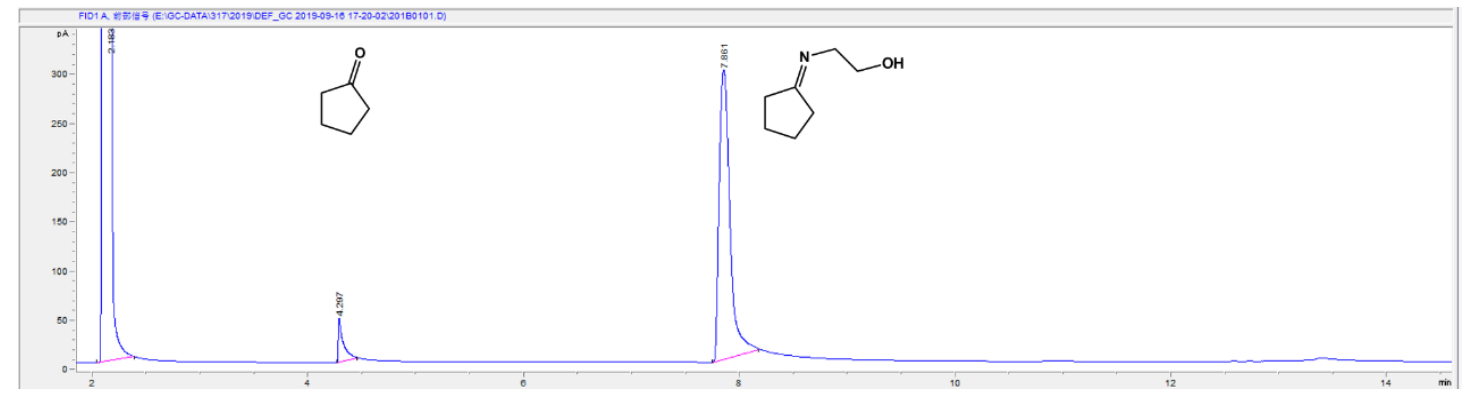

Figure S5. GC chromatogram of 2-(cyclopentylideneamino)ethanol from the reaction of cyclopentanone and ethanolamine at room temperature.

To figure out the reaction mechanism, we added equal molar of cyclopentanone and ethanolamine into a round bottom flask and stirred the mixture at room temperature. After $30 \mathrm{~min}$, a transparent bright yellow liquid was obtained. From the analysis of GC-MS and NMR (see Figures S5-S7), 2-(cyclopentylideneamino)ethanol was identified as main product from the reaction of cyclopentanone and ethanolamine. The mechanism for this reaction between cyclopentanone and ethanolamine was proposed in Scheme S1. 


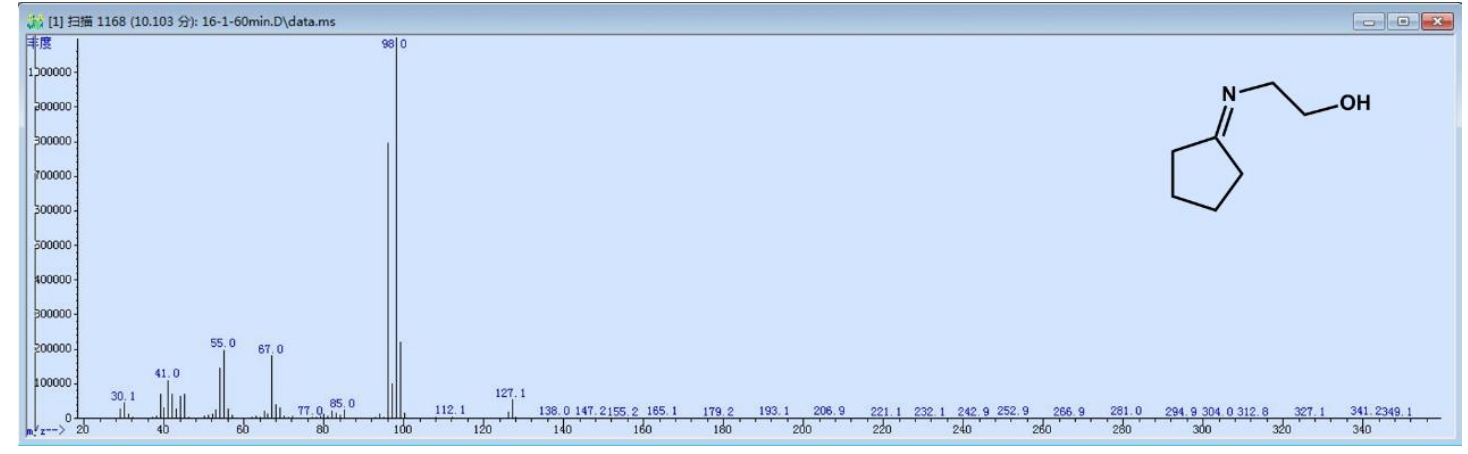

Figure S6. Mass spectrogram of 2-(cyclopentylideneamino)ethanol from the reaction of cyclopentanone and ethanolamine at room temperature. 

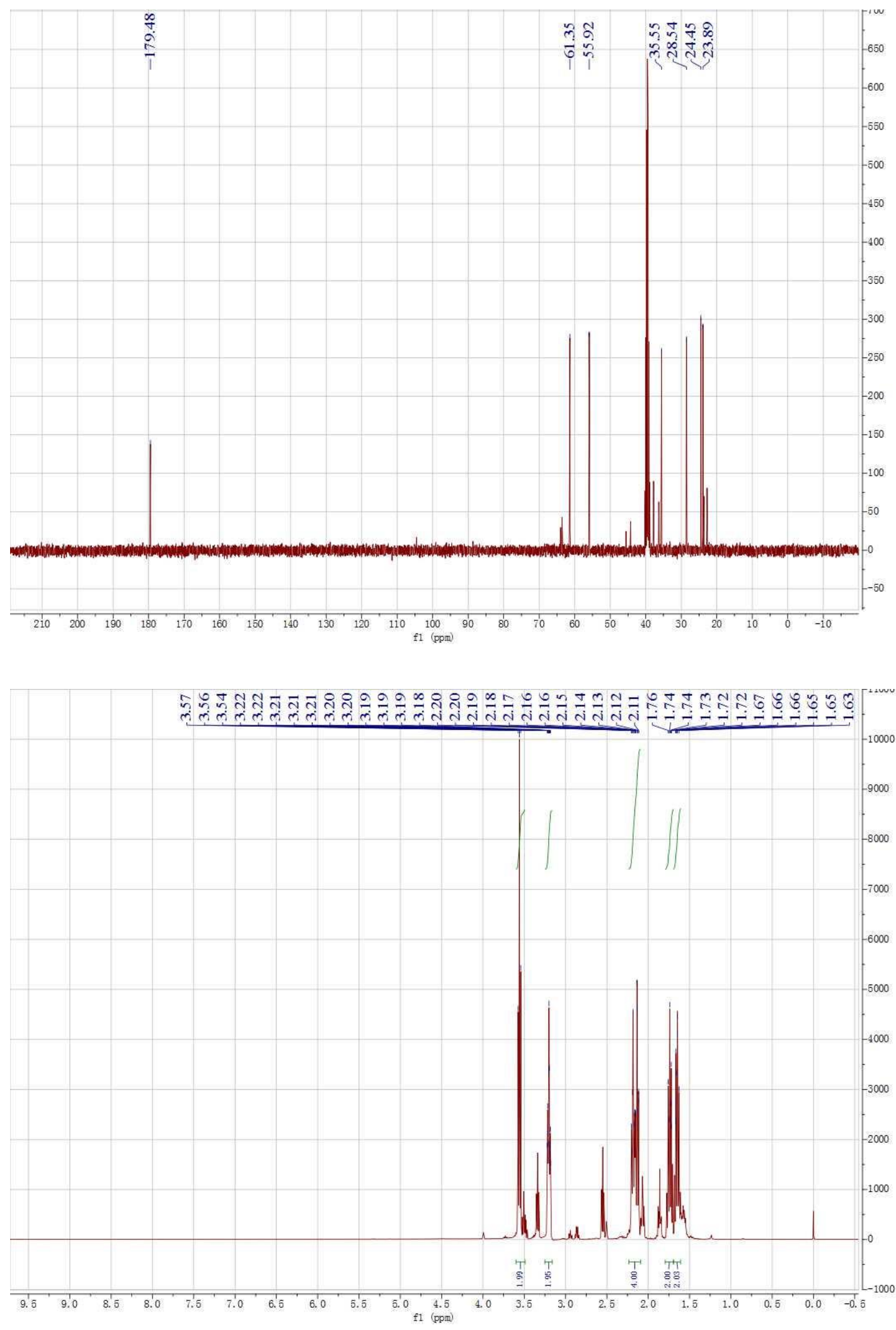

Figure S7. ${ }^{13} \mathrm{C}$ NMR and ${ }^{1} \mathrm{H}$ NMR spectra of 2-(cyclopentylideneamino)ethanol from the reaction of cyclopentanone and ethanolamine at room temperature. 


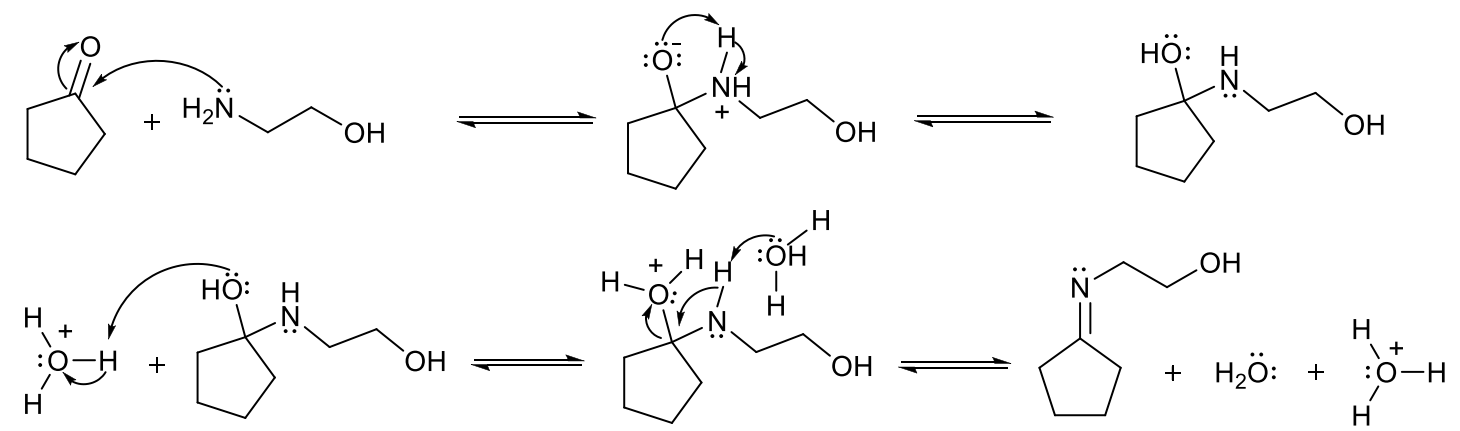

Scheme S1. Reaction mechanism for the generation of imide from cyclopentanone and ethanolamine. 


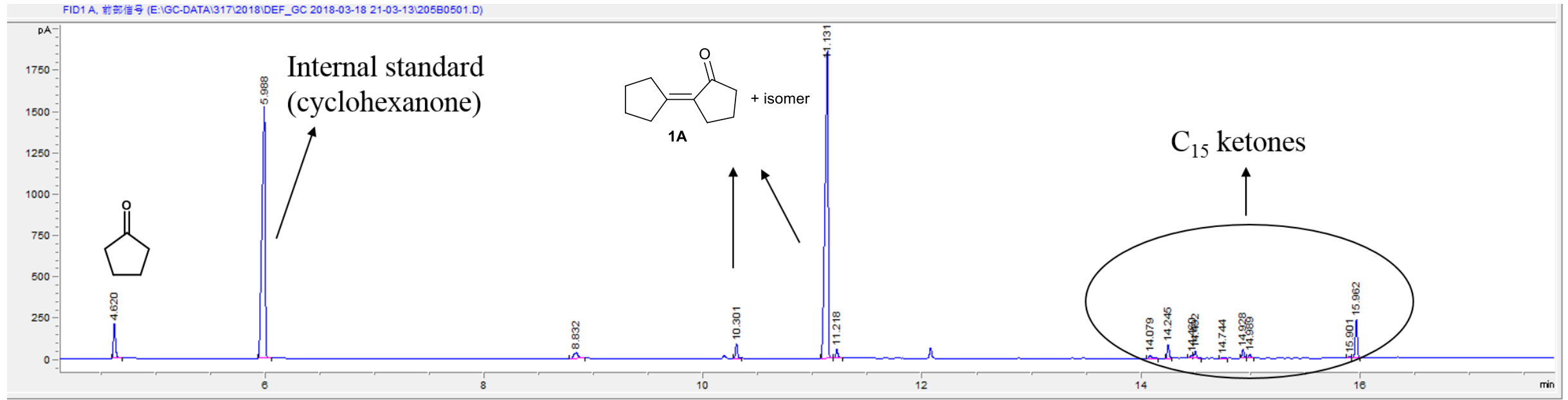

Figure S8. GC chromatogram of the solvent-free self-aldol condensation products of cyclopentanone over EAOAc ionic liquid catalyst at high reaction temperature. Reaction conditions: $393 \mathrm{~K}, 6 \mathrm{~h} ; 10 \mathrm{mmol}$ cyclopentanone and $1.5 \mathrm{mmol}$ EAOAc ionic liquid catalyst were used in the test. 
Table S1. Activation and Operation Temperatures for the Catalysts used in the Self-Aldol Condensation of Cyclopentanone.

\begin{tabular}{llll}
\hline Catalyst & Activation temperature $(\mathrm{K})$ & Operation temperature (K) & Reference \\
\hline $\mathrm{MgAl}-\mathrm{HT}$ & 723 & 423 & 1 \\
$\mathrm{MgZrO}_{2}$ & 873 & 403 & 2 \\
$\mathrm{Nb}_{2} \mathrm{O}_{5}$ & 673 & 403 \\
$\mathrm{MgO}$ & 823 & 423 \\
$\mathrm{ZrO} 2$ & 873 & 403 & 3 \\
EAOAc & Room temperature & 373 & 5 \\
\hline
\end{tabular}


Table S2. Physico-Chemical Properties of Zeolites Used in This Work. ${ }^{6}$

\begin{tabular}{ll}
\hline Zeolite & Pore size $(\AA)$ \\
\hline Y-zeolite & $7.4 \times 7.4$ \\
$\beta$-zeolite & $6.6 \times 6.75 .6 \times 5.6$ \\
ZSM-5 & $5.1 \times 5.55 .3 \times 5.6$ \\
SAPO-34 & 4.3 \\
\hline
\end{tabular}




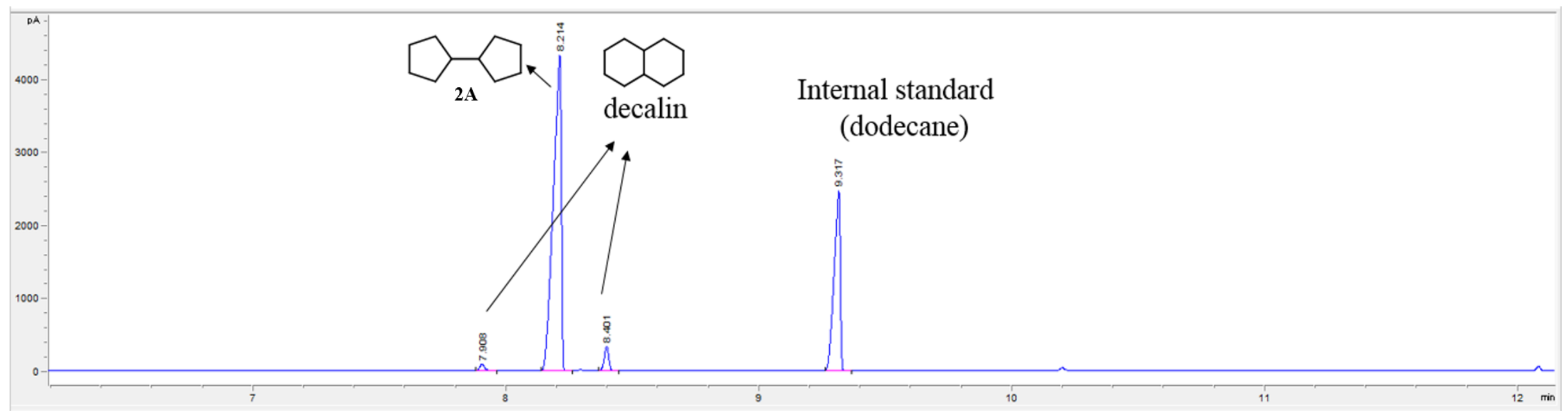

Figure S9. Gas chromatogram of the solvent-free hydrodeoxygenation (HDO) products of $\mathbf{1 A}$ over the Ru/C $+\mathrm{H}-\beta$ catalyst. Reaction conditions:

$433 \mathrm{~K}, 3 \mathrm{MPa} \mathrm{H} 2,8 \mathrm{~h} ; 30 \mathrm{~g} \mathbf{1 A}, 0.6 \mathrm{~g} \mathrm{Ru} / \mathrm{C}$ and $6.0 \mathrm{~g} \mathrm{H}-\beta$ were used in the test. 


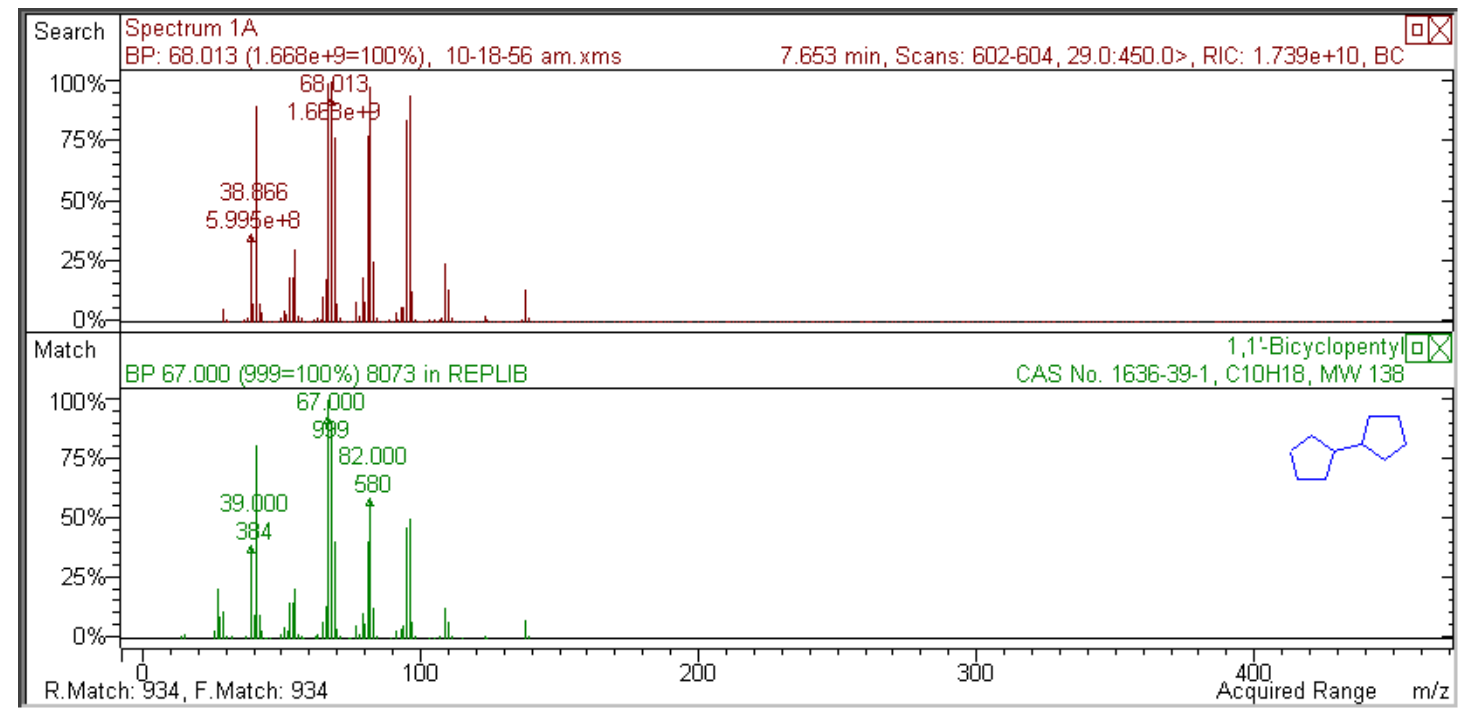

Figure S10. Mass spectrogram of $\mathbf{2 A}$ from the solvent-free HDO reaction of $\mathbf{1 A}$ over $\mathrm{Ru} / \mathrm{C}+\mathrm{H}-\beta$ catalyst. 


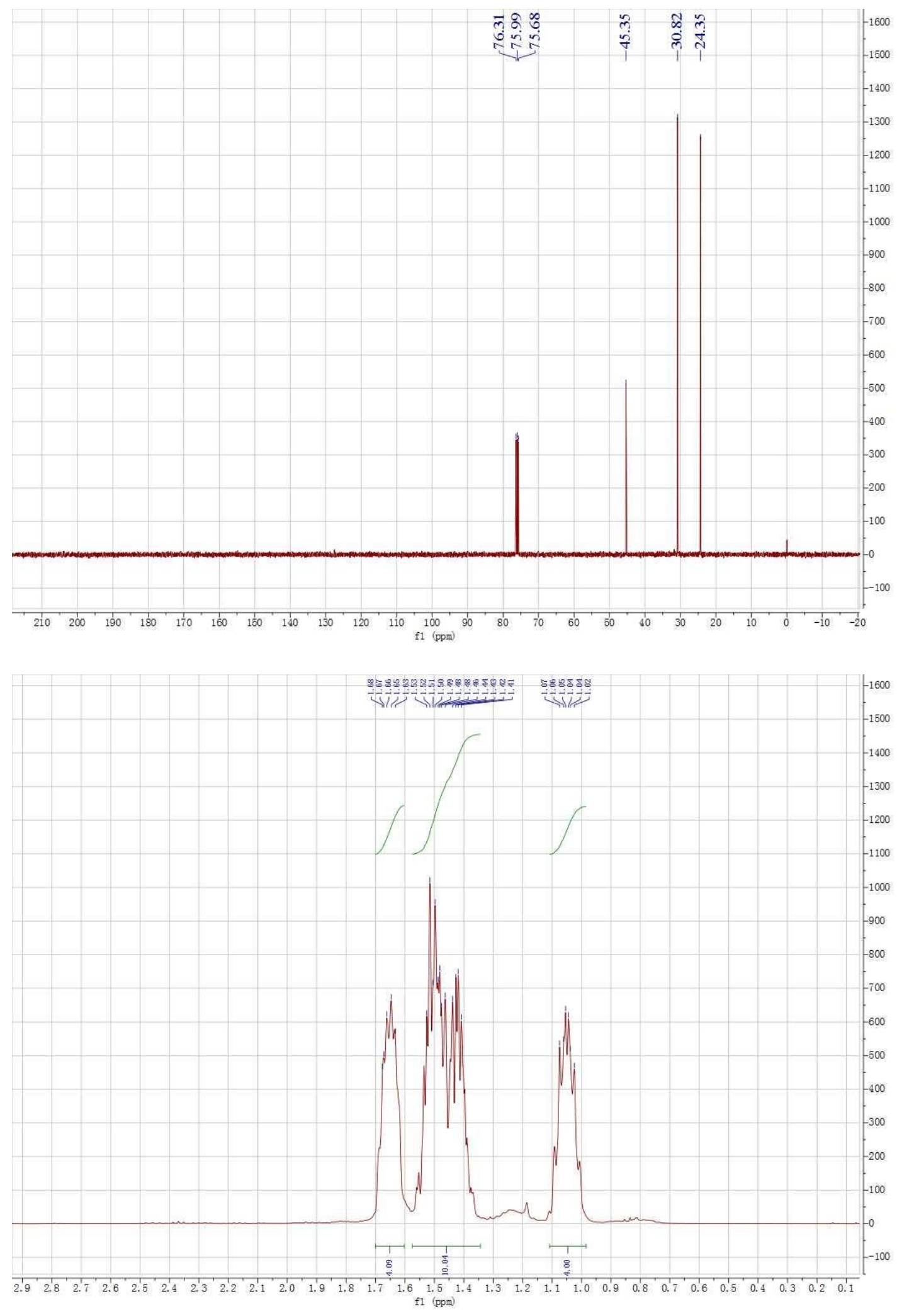

Figure S11. ${ }^{13} \mathrm{C}$ NMR and ${ }^{1} \mathrm{H}$ NMR spectra of $\mathbf{2 A}$ from the HDO of $\mathbf{1 A}$. 


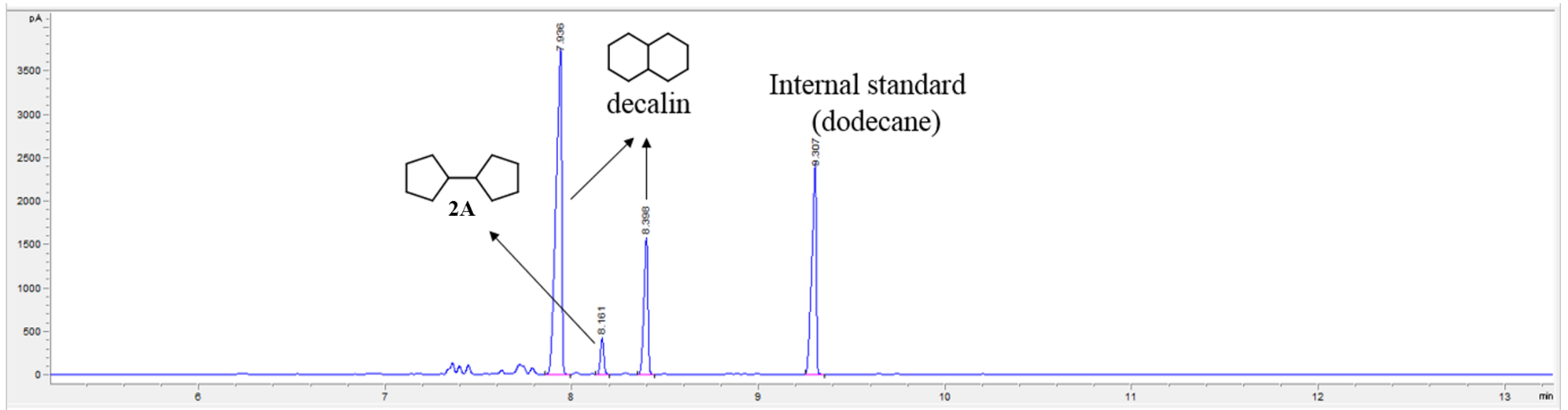

Figure S12. Gas chromatogram of the isomerization products of $\mathbf{2 A}$ over the La-Y catalyst. Reaction conditions: $443 \mathrm{~K}, 12 \mathrm{~h} ; 1 \mathrm{~g} \mathbf{2 A}, 0.1 \mathrm{~g}$ La-Y catalyst and $n$-hexane solvent were used in the test. 


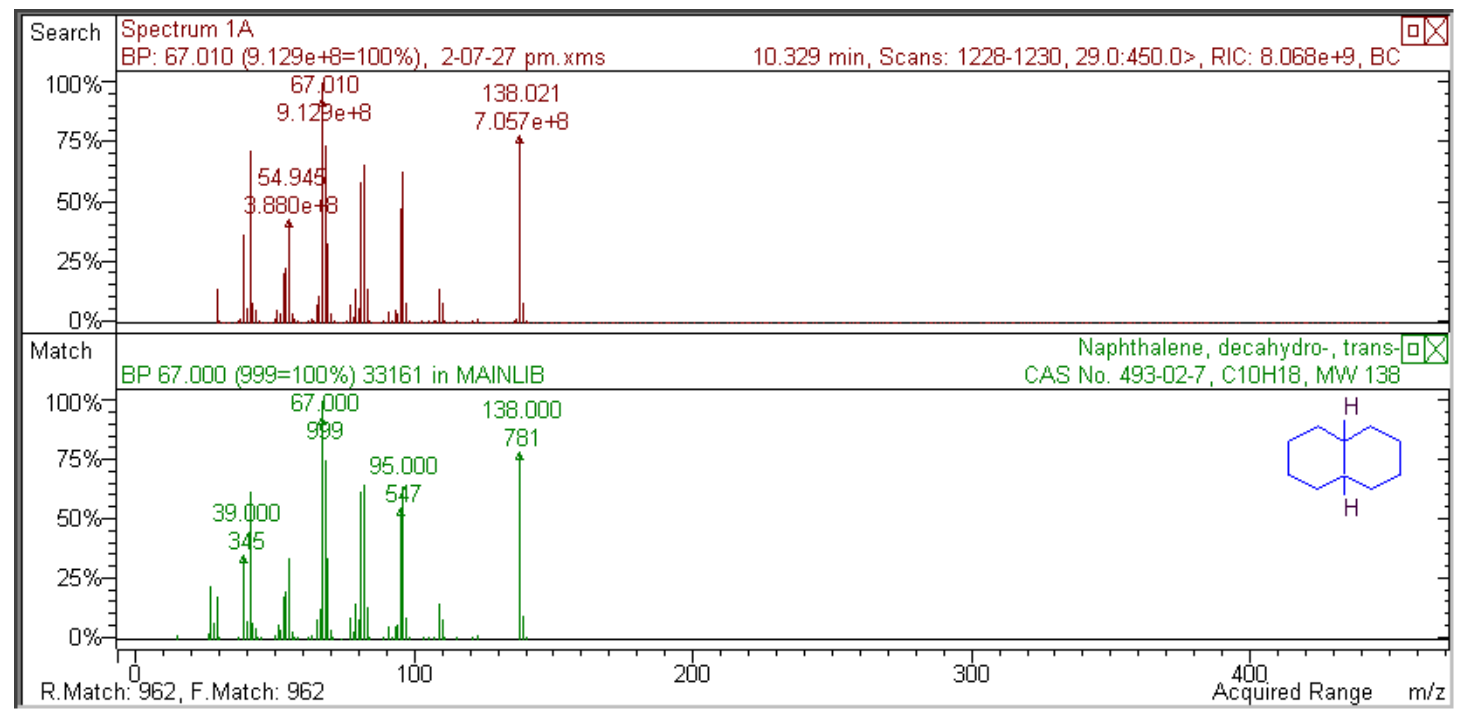

Figure S13. Mass spectrogram of decalin from the isomerization of $\mathbf{2 A}$ over La-Y catalyst. 

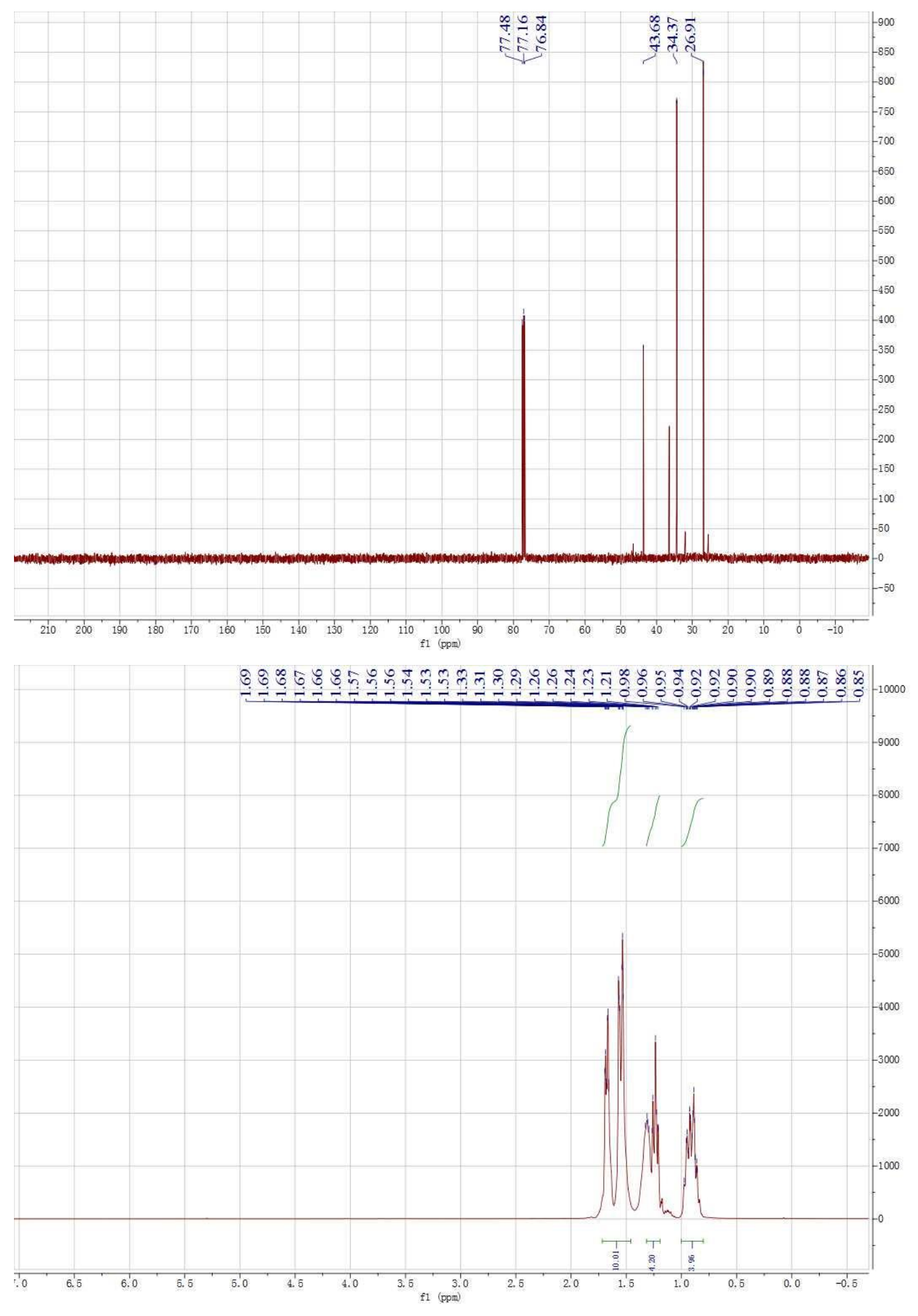

Figure S14. ${ }^{13} \mathrm{C}$ NMR and ${ }^{1} \mathrm{H}$ NMR spectra of decalin from the isomerization of $\mathbf{1 A}$. 

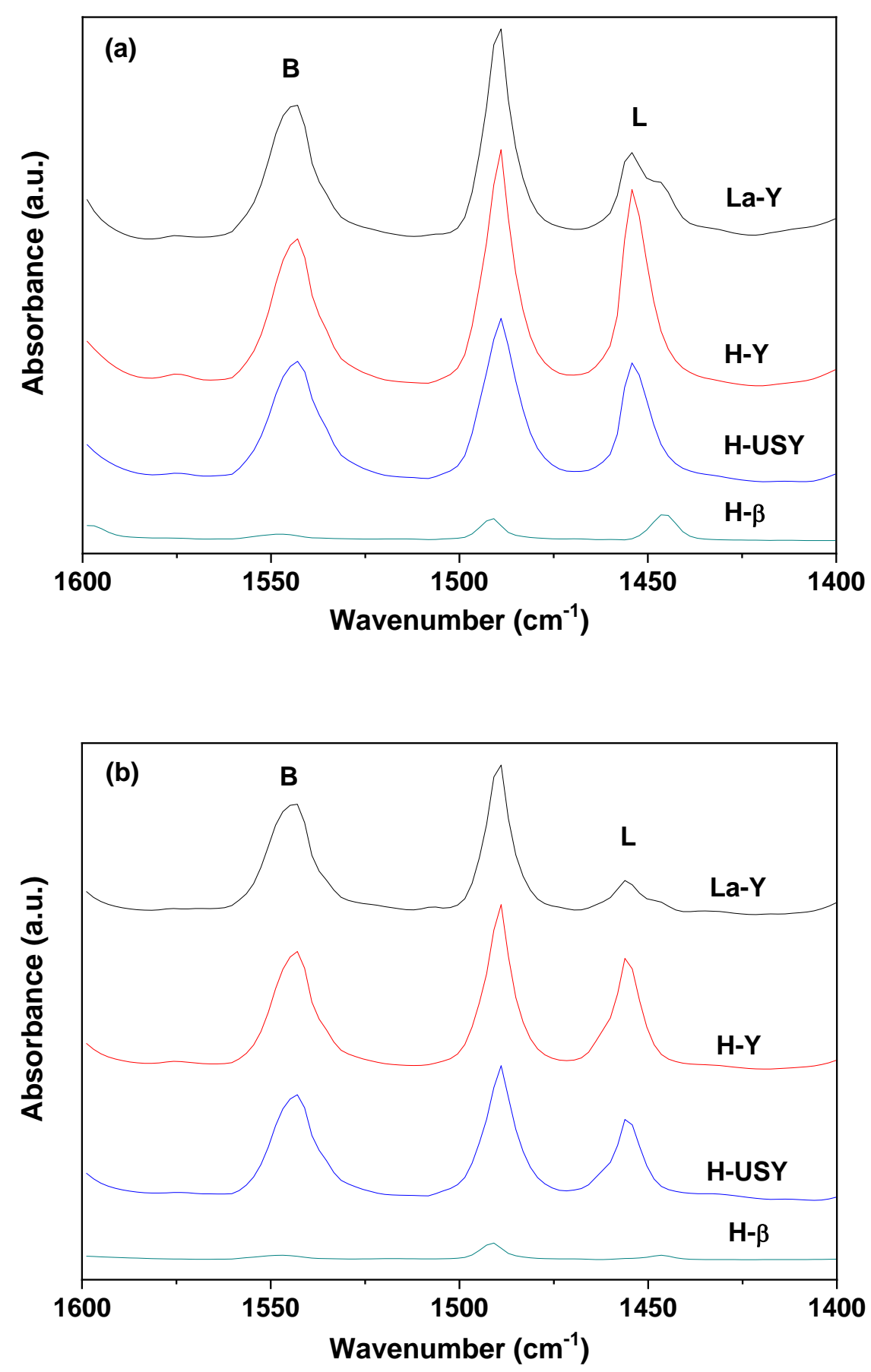

Figure S15. FT-IR spectra of different solid acid catalysts after the adsorption of pyridine and vacuation at $443 \mathrm{~K}$ (a) or $623 \mathrm{~K}$ (b). B: Brønsted acid sites; L: Lewis acid sites. 
Table S3. Freezing Points of Different Products.

\section{Freezing point $(\mathrm{K})^{\mathrm{a}}$}

Aldol condensation/hydrodeoxygenation products

Cyclopentanone route

281.1

Cyclohexanone route
Aldol condensation/hydrodeoxygenation/isomerization products

231.8

249.7

a The freezing points of different products were determined by a PFA-70Xi freezing point analyzer. Before the measurements, the samples were dehydrated with anhydrous sodium sulfate. 


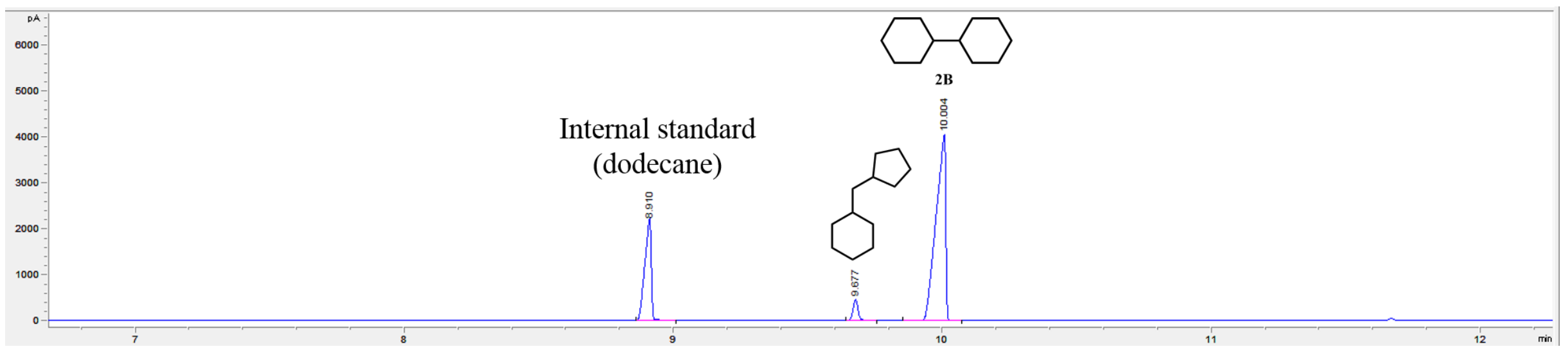

Figure S16. Gas chromatogram of the solvent-free $\mathrm{HDO}$ products of $\mathbf{1 B}$ over the $\mathrm{Ru} / \mathrm{C}+\mathrm{H}-\beta$ catalyst. Reaction conditions: $433 \mathrm{~K}, 3 \mathrm{MPa} \mathrm{H}_{2}, 8$ $\mathrm{h} ; 30 \mathrm{~g} \mathrm{1B}, 0.6 \mathrm{~g} \mathrm{Ru} / \mathrm{C}$ and $6.0 \mathrm{~g} \mathrm{H}-\beta$ were used in the test. 


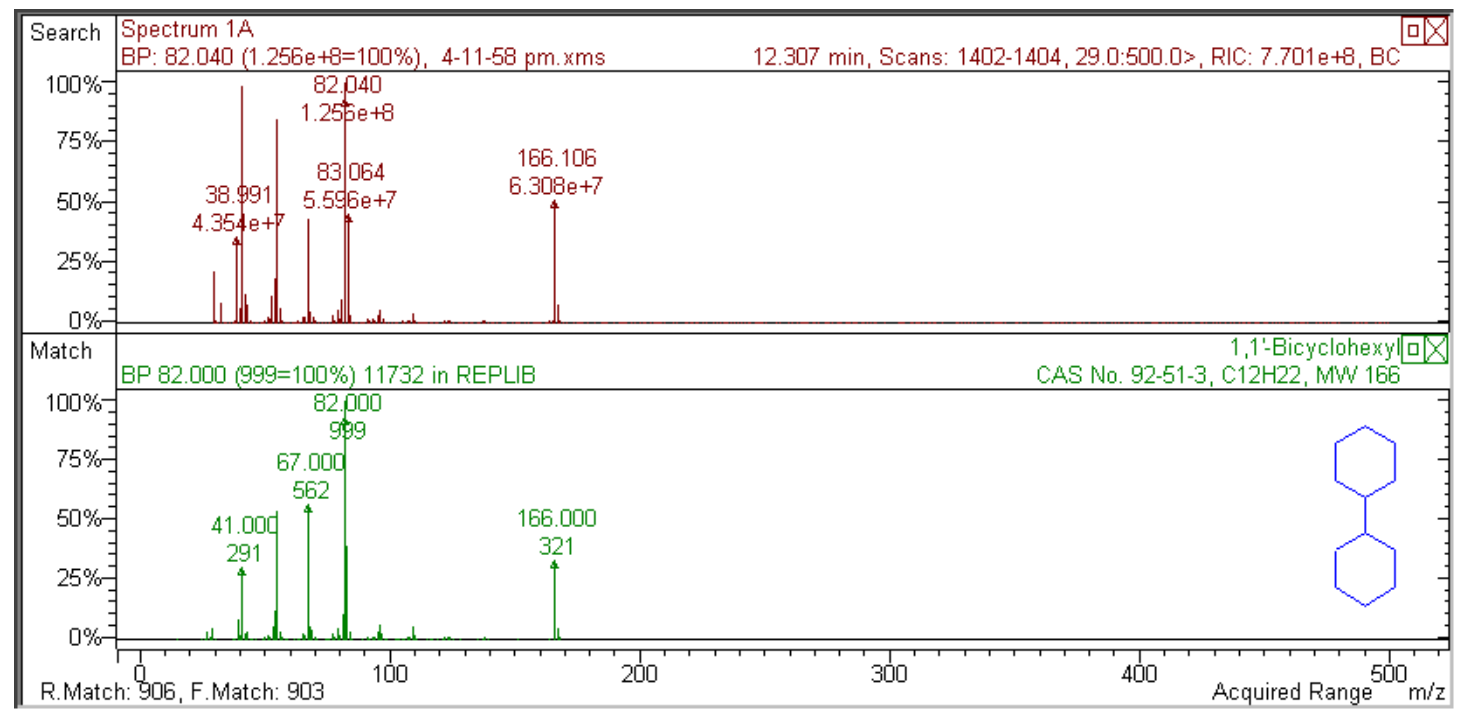

Figure S17. Mass spectrogram of 2B from the solvent-free HDO reaction of 1B over

$\mathrm{Ru} / \mathrm{C}+\mathrm{H}-\beta$ catalyst. 


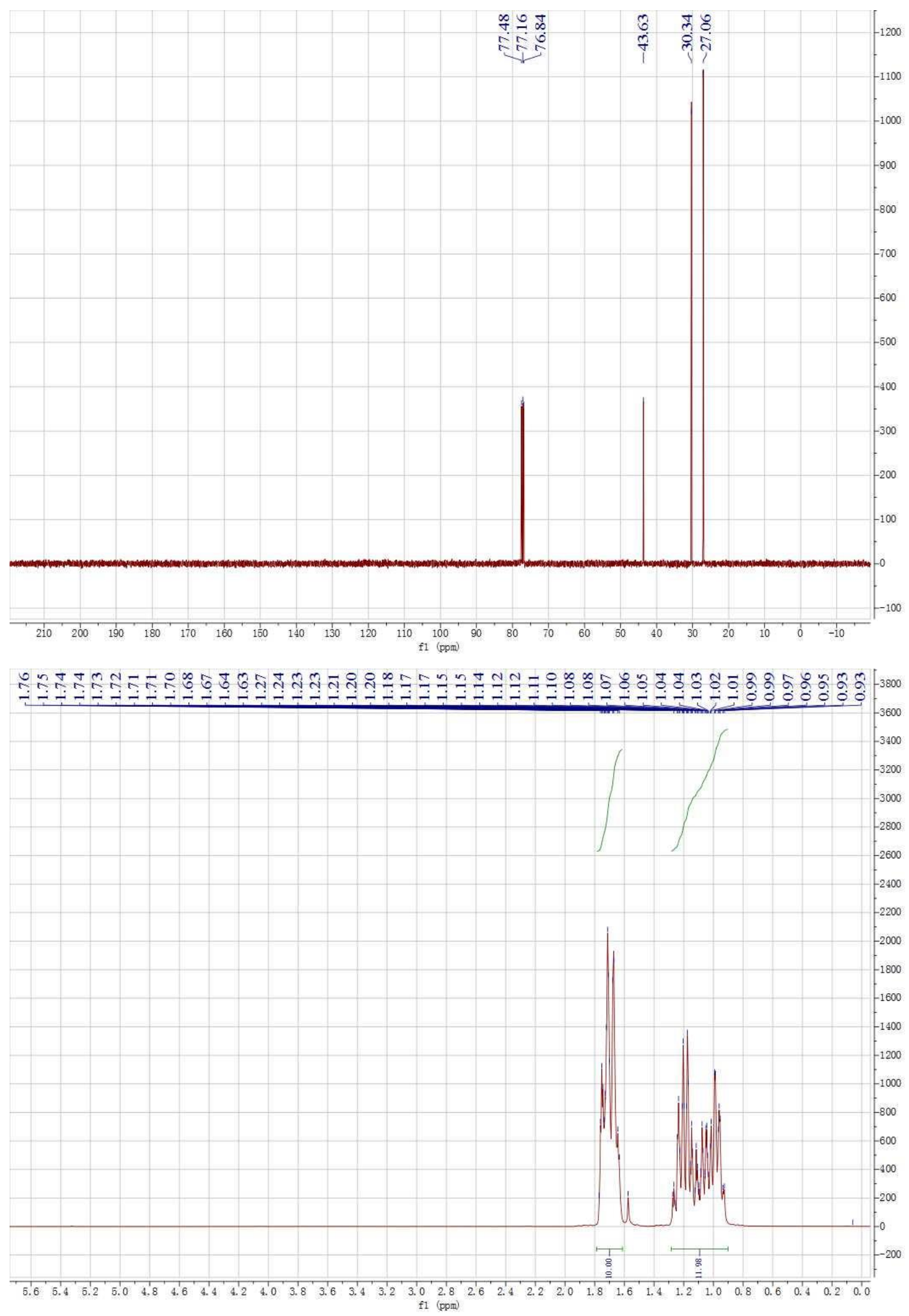

Figure S18. ${ }^{13} \mathrm{C}$ NMR and ${ }^{1} \mathrm{H}$ NMR spectra of $\mathbf{2 B}$ from the solvent-free HDO reaction of $1 B$ over $\mathrm{Ru} / \mathrm{C}+\mathrm{H}-\beta$ catalyst. 


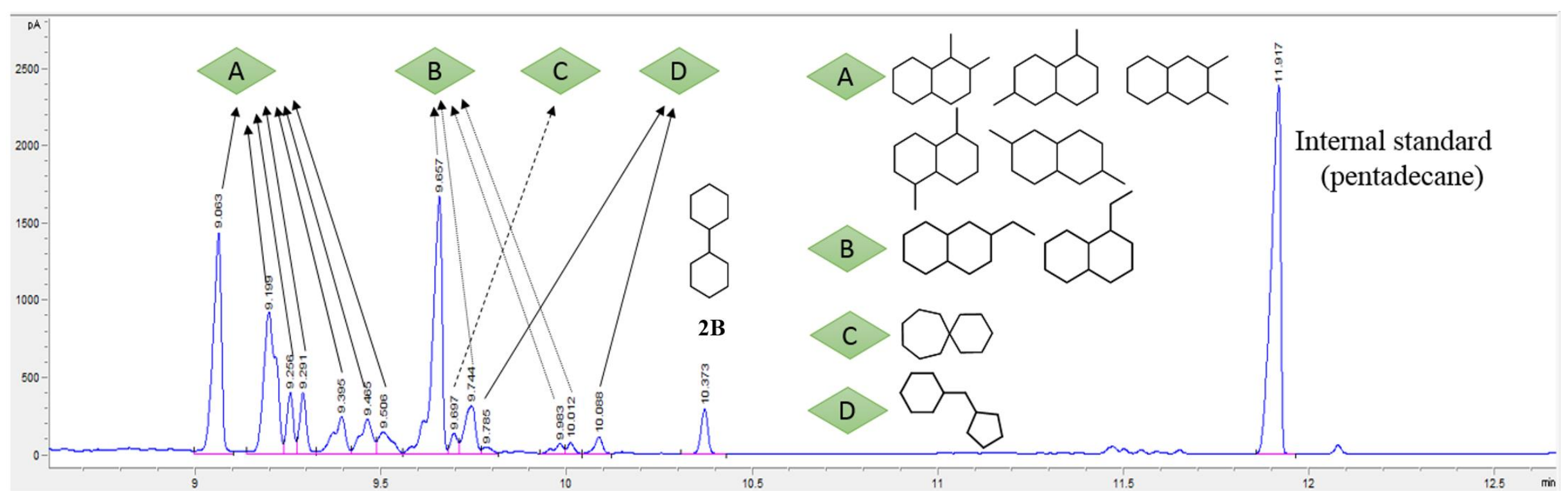

Figure S19. Gas chromatogram of the isomerization products of $\mathbf{2 B}$ over the La-Y catalyst. Reaction conditions: $443 \mathrm{~K}, 12 \mathrm{~h}$; $1 \mathrm{~g} \mathrm{2B}, 0.2 \mathrm{~g}$ La-Y catalyst and $n$-hexane solvent were used in the test. 

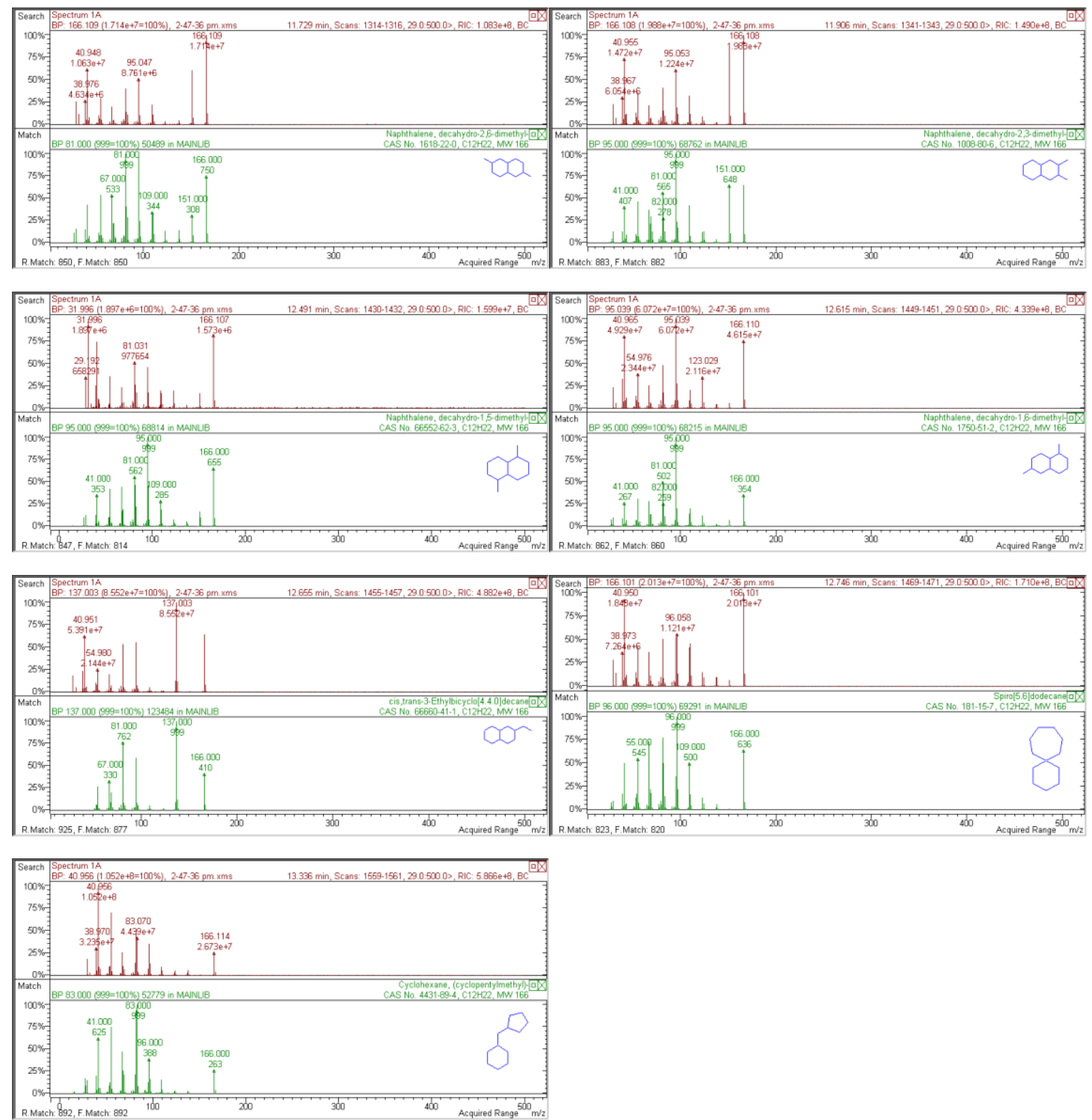

Figure S20. Mass spectrograms of the isomerization products of 2B over La-Y catalyst. 


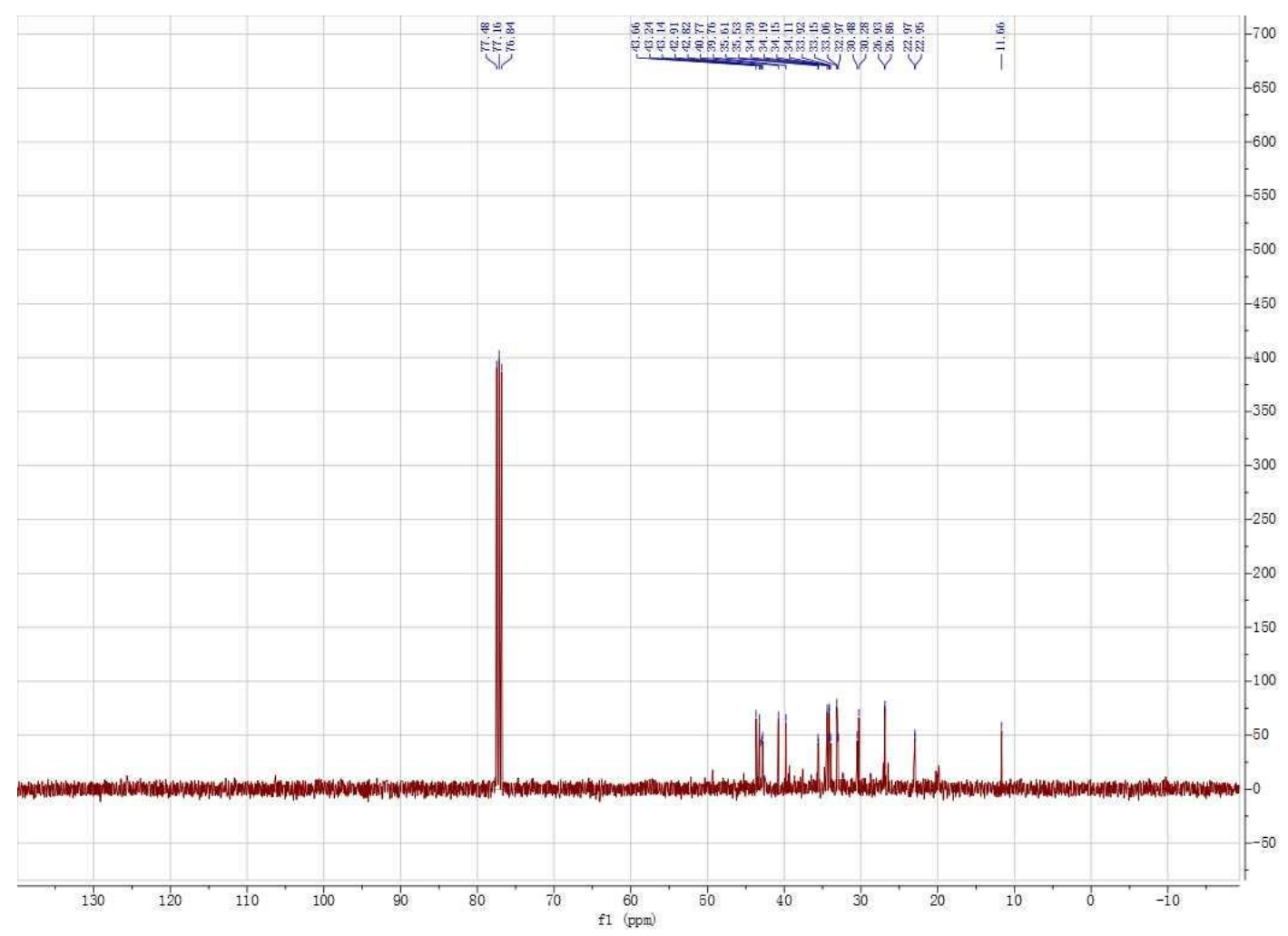

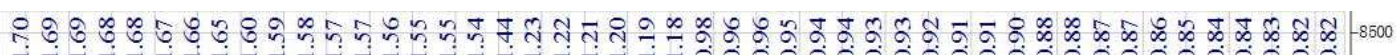

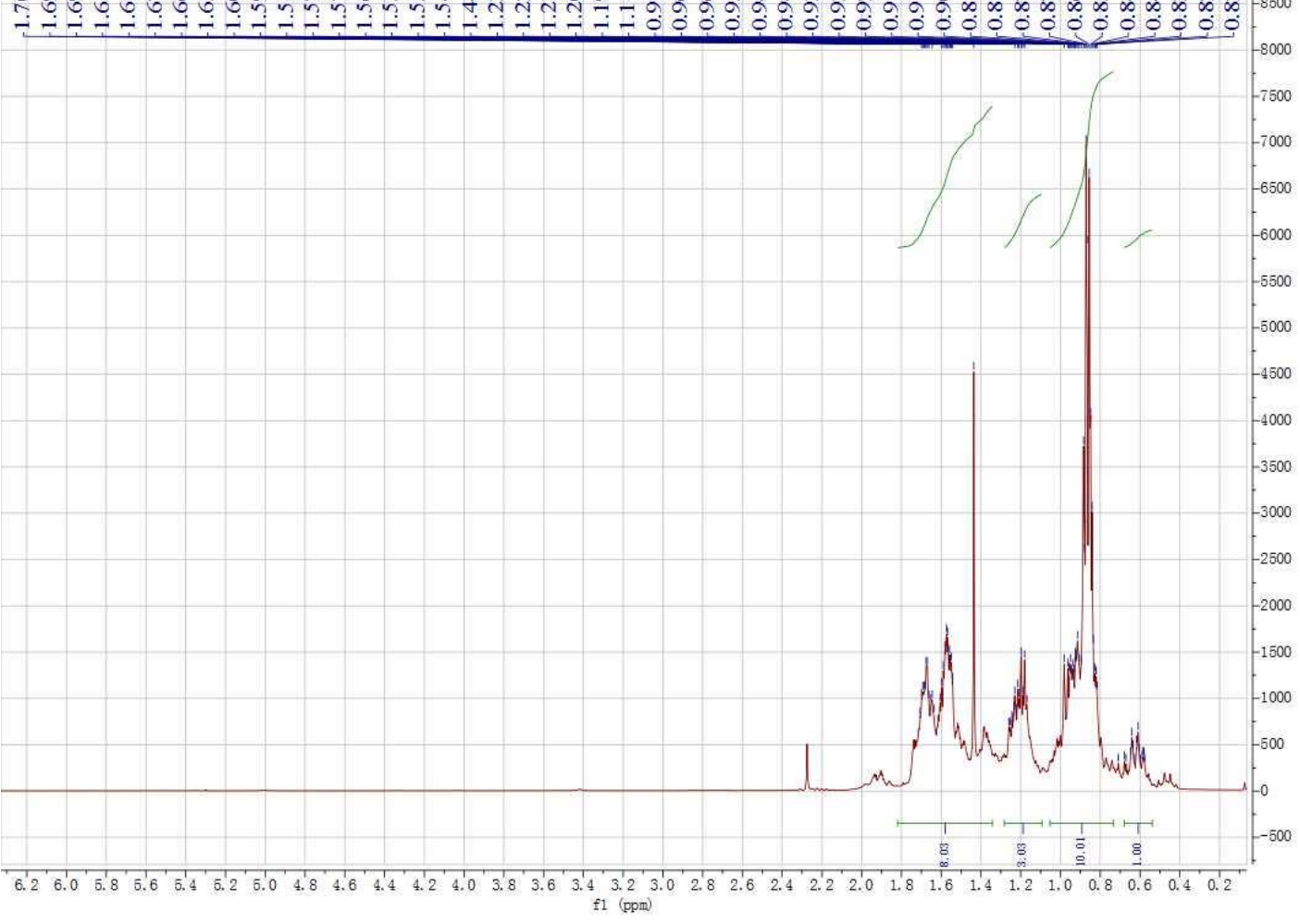

Figure S21. ${ }^{13} \mathrm{C}$ NMR and ${ }^{1} \mathrm{H}$ NMR spectra of the isomerization products of $\mathbf{2 B}$ over La-Y catalyst. 


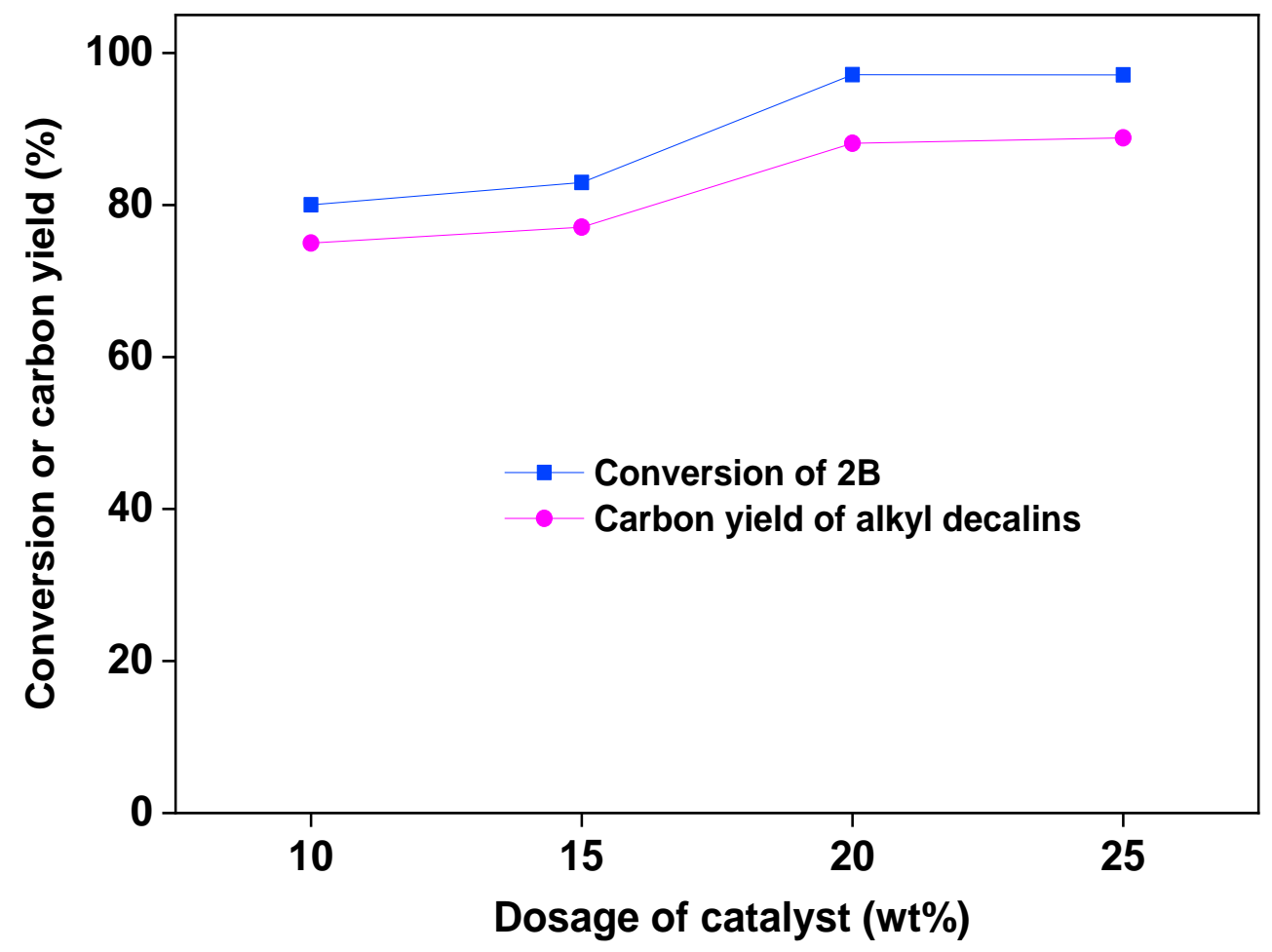

Figure S22. Conversion of 2B and the carbon yield of alkyl decalins over La-Y as the function of catalyst dosage. Reaction conditions: $443 \mathrm{~K}, 12 \mathrm{~h} ; 1 \mathrm{~g} \mathrm{2B}$, La-Y and $n$-hexane solvent were used in each test. 


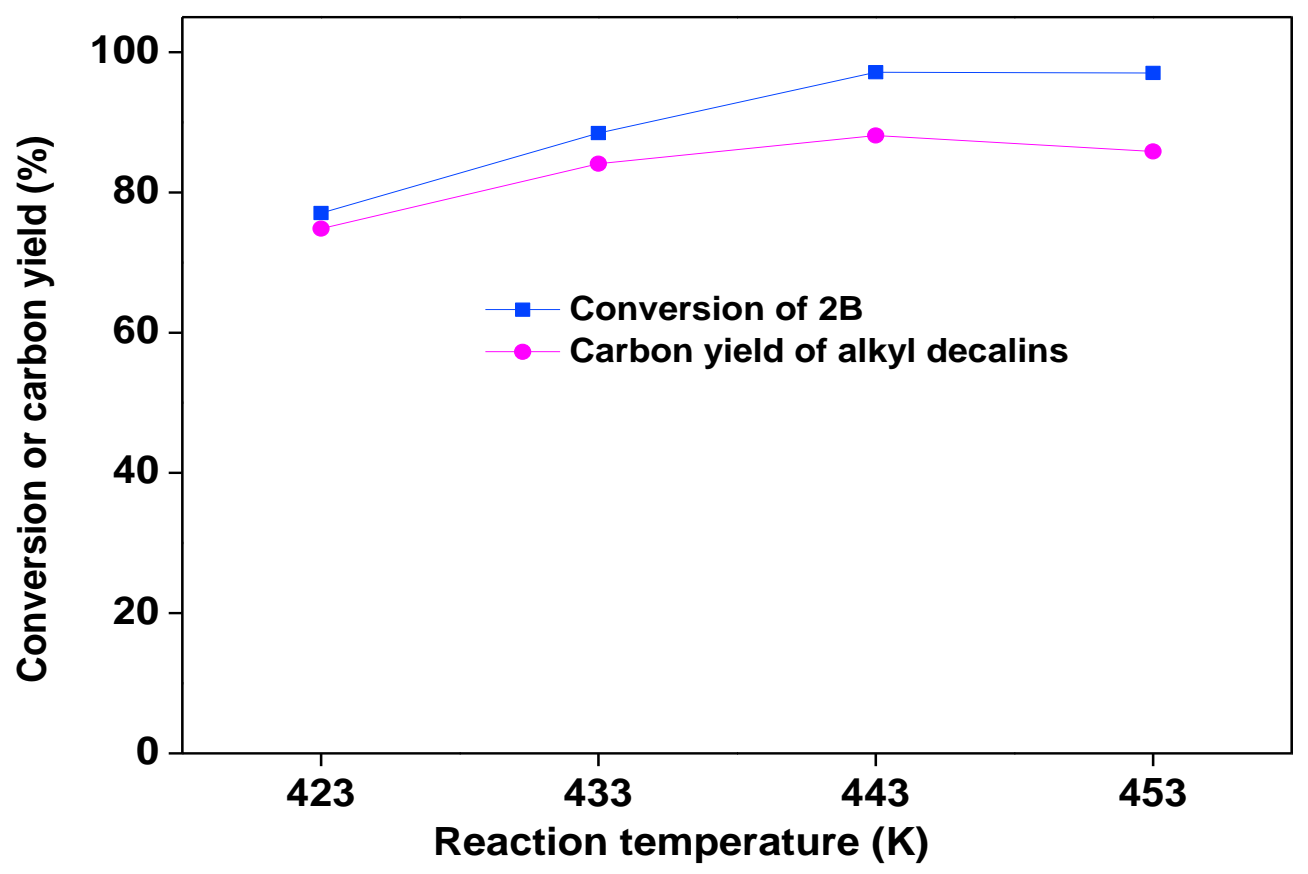

Figure S23. Conversions of 2B and the carbon yield of alkyl decalins over La-Y catalyst as the function of reaction temperature. Reaction conditions: $12 \mathrm{~h} ; 1 \mathrm{~g} \mathrm{2B}, 0.2$ g La-Y and $n$-hexane solvent were used in each test. 


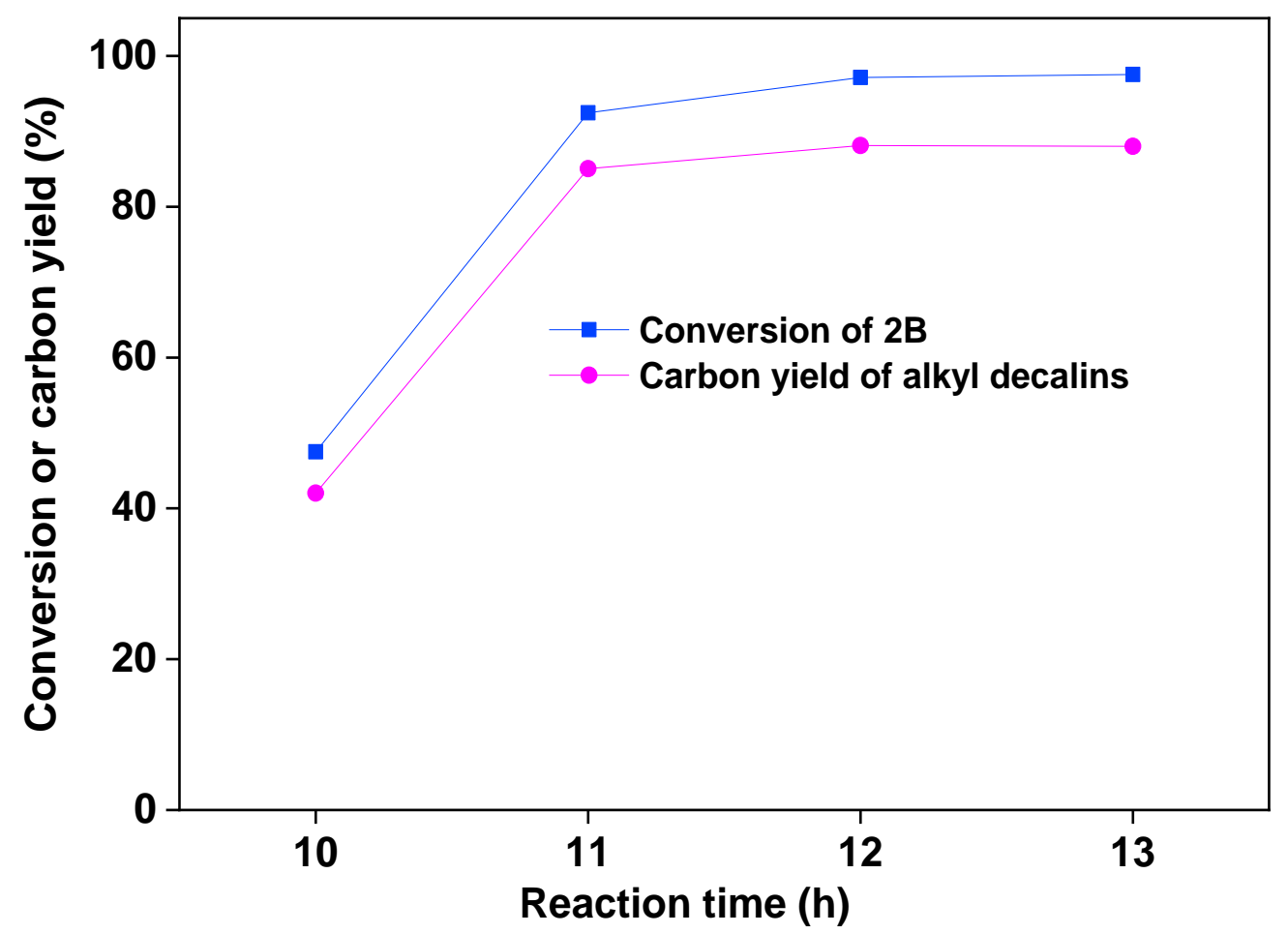

Figure S24. Conversion of 2B and the carbon yield of alkyl decalins over La-Y catalyst as the function of reaction time. Reaction conditions: $443 \mathrm{~K} ; 1 \mathrm{~g} \mathrm{2B}, 0.2 \mathrm{~g}$ La-Y and $n$-hexane solvent were used in each test. 


\section{Reference}

(1) Yang, J.; Li, N.; Li, G.; Wang, W.; Wang, A.; Wang, X.; Cong, Y.; Zhang, T., Synthesis of renewable high-density fuels using cyclopentanone derived from lignocellulose. Chem. Commun. (Cambridge, U. K.) 2014, 50, 2572-2574, Doi:10.1039/c3cc46588h.

(2) Liang, D.; Li, G.; Liu, Y.; Wu, J.; Zhang, X., Controllable self-aldol condensation of cyclopentanone over $\mathrm{MgO}-\mathrm{ZrO}_{2}$ mixed oxides: Origin of activity \&amp; selectivity. Catal. Commun. 2016, 81, 33-36, Doi:10.1016/j.catcom.2016.04.008.

(3) Jing, Y.; Xin, Y.; Guo, Y.; Liu, X.; Wang, Y., Highly efficient $\mathrm{Nb}_{2} \mathrm{O}_{5}$ catalyst for aldol condensation of biomass-derived carbonyl molecules to fuel precursors. Chin. J. Catal. 2019, 40, 1168-1177, Doi:10.1016/S1872-2067(19)63371-1.

(4) Ngo, D. T.; Sooknoi, T.; Resasco, D. E., Improving stability of cyclopentanone aldol condensation MgO-based catalysts by surface hydrophobization with organosilanes. Appl. Catal., B 2018, 237, 835-843, Doi:10.1016/j.apcatb.2018.06.044.

(5) Wan, M.; Liang, D.; Wang, L.; Zhang, X.; Yang, D.; Li, G., Cycloketone condensation catalyzed by zirconia: Origin of reactant selectivity. J. Catal. 2018, 361, 186-192, Doi:10.1016/j.jcat.2018.02.021.

(6) Jae, J.; Tompsett, G. A.; Foster, A. J.; Hammond, K. D.; Auerbach, S. M.; Lobo, R. F.; Huber, G. W., Investigation into the shape selectivity of zeolite catalysts for biomass conversion. J. Catal. 2011, 279, 257-268, Doi:10.1016/j.jcat.2011.01.019. 